\title{
PENGARUH DISIPLIN KERJA DAN PELATIHAN BROADBRAND LEARNING CENTER (BLC) TERHADAP KINERJA PEGAWAI NEGERI SIPIL (Studi Kasus di Wilayah Kecamatan Benowo Kota Surabaya)
}

\author{
Yunni Rusmawati Dj \\ Fakultas Ekonomi, Universitas Islam Lamongan \\ yunnirusmawatidj@gmail.com \\ Nurus Safa'atillah \\ Fakultas Ekonomi, Universitas Islam Lamongan \\ nurus_safa'atillah@yahoo.com
}

\begin{abstract}
ABSTRAK
Pegawai Negeri Sipil Pemkot Surabaya guna meningkatkan kualitas pelayanan kepada masyarakat dan dengan adanya surat edaran dari walikota yang menyatakan bahwa terdapat himbauan untuk pelayanan 24 jam dengan ketentuan penambahan hari efektif kerja serta jam kerja yang semula hari Sabtu merupakan hari libur bagi PNS tetapi mulai bulan Mei 2017 PNS di Surabaya Sabtu tetap masuk kerja dimulai pukul 09.00-14.00 WIB. Dalam hal ini disiplin kerja sangat ditekankan oleh walikota Surabaya mulai dari absensi kehadiran sampai pulang pun ada penawasan dalam absensi maupun kualitas kerja. Dinas Komunikasi dan Informatika Pemkot Surabaya merupakan instansi Pemerintah yang mencoba memberikan fasilitas kepada masyarakat yang ada di Surabaya agar dapat tanggap dan mengikuti perkembangan teknologi sehingga dapat berkontribusi dalam pembangunan Kota Surabaya. Oleh karena itu, dibentuklah program pelatihan internet yaitu Broadbrand Learning Center (BLC) yang merupakan program literasi internet berupa pelatihan beragam materi tentang Tehnologi Informasi dan Komunikasi (TIK) bagi warga Surabaya yang diberikan secara gratis dan bersertifikat, dilengkapi dengan berbagai fasilitas pendukung yang juga dapat dimanfaatkan pengunjung untuk menggunakan fasilitas internet serta free wifi. Berdasarkan hasil pembahasan analisis data dalam bab sebelumnya, maka dapat ditarik kesimpulan sebagai berikut : antara disiplin kerja dan pelatihan BLC, variabel yang memiliki pengaruh paling dominan terhadap kinerja pegawai negeri sipil di Wilayah Kecamatan Benowo Kota Surabaya adalah variabel pelatihan BLC. Karena dari hasil penelitian Koefisien Beta menunjukan bahwa nilai variabel disiplin kerja sebesar 0,360. Sedangkan nilai variabel pelatihan BLC sebesar 0,504. Oleh karena nilai variabel pelatihan BLC lebih besar, maka yang paling dominan berpengaruh terhadap kinerja pegawai negeri sipil di Wilayah Kecamatan Benowo Kota Surabaya.
\end{abstract}

Kata Kunci : Pelatihan Broadbrand Learning Center (BLC), Kinerja 


\section{PENDAHULUAN}

Dinas Komunikasi dan Informatika Pemerintah Kota Surabaya merupakan instansi pemerintah di bidang IT sekaligus diharapkam mampu memproduksi konten informasi, sehingga dapat berkontribusi dalam pembangunan Kota Surabaya. Dinas Komunikasi dan Informatika (Kominfo) menjalankan perannya sebagai humas pemerintah serta menciptakan masyarakat melek IT yang juga mampu memproduksi informasi. Dinas Kominfo Pemkot Surabaya telah menyediakan fasilitas internet gratis di 42 titik taman kota di Surabaya yang bias diakses warga selama 24 jam. Diantara titik hot spot yang bias dimanfaatkan yaitu di Taman Bungkul yang berlokasi di Jl Raya Darmo. Tujuannya agar masyarakat kota Surabaya lebih mudah untuk memperoleh bergamam informasi secara online. Oleh karena itu, dibentuklah program pelatihan internet yaitu Broadbrand Learning Center (BLC) yang merupakan program literasi internet berupa pelatihan beragam materi tentang Tehnologi Informasi dan Komunikasi (TIK) bagi warga Surabaya yang diberikan secara gratis dan bersertifikat, dilengkapi dengan berbagai fasilitas pendukung yang juga dapat dimanfaatkan pengunjung untuk menggunakan fasilitas internet serta free wifi. Dalam penelitian ini terungkap bahwa Dinas Kominfo bersama jajaran tim tenaga pegajar (instruktur) BLC berperan sebagai penggerak komunitas dengan memberikan stimuli serta mengajak masyarakat kota Surabaya agar mau belajar TIK. Tidak hanya cukup sampai pada fase pemahaman dan penguasaan TIK saja, melainkan mendorong masyarakat agar mampu memanfaatkan teknologi informasi untuk memenuhi kebutuhan hidupnya.

Dengan adanya peningkatan kualitas hidup masyarakat berkat melek IT tersebut, maka secara otomatis akan ikut meningkatkan daya saing Kota Surabaya. Pemkot Surabaya akan lebih mudah di dalam menerapkan berbagai kebijakannya yang saat ini telah memberlakukan system $e$-Government.

Pegawai Negeri Sipil di Surabaya mulai bulan Mei 2017 menurut surat edaran walikota menyatakan bahwa pegawai negeri sipil di Surabaya pada hari sabtu masuk untuk tetap senantiasa memberikan pelayanan kepada masyarakat. Jam kerja Pegawai Negeri Sipil di Surabaya pada hari Senin Jum'at dimulai pukul 07.30 WIB dan diakhiri pukul 16.00 WIB sedangkan di 
hari sabtu dimulai pukul 09.00 WIB sampai pukul 14.00 WIB. Dalam hal ini disiplin kerja pegawai negeri sipil sangat dituntut guna meningkatkan tingkat kepuasan pelayanan kepada masyarakat serta kinerja pegawai negeri sipil.

Surabaya Barat dahulu merupakan wilayah yang terpencil dan pinggiran bahkan banyak yang mengatakan bahwa wilayah Surabaya Barat adalah daerah desanya Surabaya namun fenomena tersebut berbanding terbalik dengan keadaan sekarang justru Surabaya Barat sekarang merupakan wilayah yang padat penduduknya dan daerah rawan kemacetan.

Di Surabaya barat terdapat Kecamatan Benowo terbagi menjadi Kelurahan Kandangan, Kelurahan Klakahrejo, Kelurahan Romokalisari, Kelurahan Sememi, Kelurahan Tambak Oso Wilangun. Pada setiap instansi Kelurahan terdapat Pegawai Negeri Sipil yang bertugas melayani masyarakat dalam pembuatan Akte Kelahiran, pembuatan Kartu Keluarga, Pembuatan Kartu Tanda Penduduk dan semua berbasis komputerisasi yang mana menuntut para Pegawai Negeri Sipil (PNS) menjadi Sumber Daya Manusia yang berkualitas, modernisasi dalam teknologi, berkompeten dan mampu melayani masyarakat dengan baik. Pelatihan Broadband Learning Center (BLC) dapat dijadikan wahana dalam peningkatan dan pengembangan kompetensi para Pegawai Negeri Sipil di kawasan Surabaya Barat dan di Kecamatan Benowo khususnya yang nantinya dapat membatu dalam proses pelayanan masyarakat.

Tujuan penelitian ini adalah untuk :

1. Untuk mengetahui secara parsial pengaruh disiplin kerja dan pelatihan Broadbrand Learning Center (BLC) terhadap Kinerja Pegawai Negeri Sipil (Studi Kasus di Wilayah Kecamatan Benowo Kota Surabaya).

2. Untuk mengetahui secara dominan pengaruh disiplin kerja dan pelatihan Broadbrand Learning Center (BLC) terhadap Kinerja Pegawai Negeri Sipil (Studi Kasus di Wilayah Kecamatan Benowo Kota Surabaya).

3. Untuk mengetahui variabel mana yang paling dominan yang mempengaruhi kinerja Pegawai Negeri Sipil (Studi Kasus di Wilayah Kecamatan Benowo Kota Surabaya). 


\section{TINJAUAN PUSTAKA}

\subsection{Pengertian Disiplin Kerja}

Menurut Hasibuan (2008:193) menyatakan bahwa "Disiplin adalah kesadaran dan kesediaan seseorang mentaati semua peraturan perusahaan dan norma-norma sosial yang berlaku”. Sedangkan menurut Mangkunegara (2013:129) menyatakan: Disiplin korektif adalah suatu upaya menggerakkan pegawai dalam menyatukan suatu peraturan dan mengarahkan untuk tetap mematuhi peraturan sesuai dengan yang berlaku di perusahaan.

\subsection{Pengertian Pelatihan}

Menurut Mangkuprawira (2010) adalah sebuah proses mengajarkan pengetahuan dan keahlian tertentu serta sikap agar karyawan semakin terampil dan mampu melaksanakan tanggung jawab dengan semakin baik, sesuai dengan standar. Sedangkan Menurut Dessler (2014) bahwa "Pelatihan merupakan proses mengajar ketrampilan yang dibutuhkan karyawan untuk melakukan pekerjaannya". Jenisjenis pelatihan yang terdapat didalam organisasi: (a) Pelatihan keahlian. (b) Pelatihan ulang. (c) Pelatihan lintas fungsional. (d) Pelatihan tim. (e) Pelatihan kreativitas (Simamora 2006).

\subsection{Pengertian Kinerja}

Menurut Mangkunegara (2010) "Kinerja adalah hasil kerja secara kualitas dan kuantitas yang dicapai oleh seseorang karyawan dalam melaksanakan tugasnya sesuai dengan tanggung jawab yang diberikan kepadanya". Sedangkan menurut Simamora (2006) "Kinerja merupakan proses dengannya organisasi mengevaluasi pelaksanaan kerja individu. Penilaian kinerja dilakukan melalui konstribusi karyawan terhadap organisasi selama periode waktu tertentu".

Menurut Gomez (2010) ukuran perfomansi yang bersifat kuantitatif seperti satuan- satuan produksi dan volume penjualan menghasilkan pengukuran yang konsisten secara relatif. Kriteria-kriteria yang bersifat subyektif, seperti sikap, kreativitas, dan kerja sama, menghasilkan pengukuran yang kurang konsisten tergantung pada siapa yang mengevaluasi, dan bagaimana pengukuran itu dilakukan. Komponen utama penilaian kinerja itu adalah sebagai berikut : 
1. Quantity of work, yaitu jumlah hasil kerja yang didapat dalam suatu periode waktu yang ditentukan;

2. Quality of work, yaitu mutu pekerjaan yang dihasilkan berdasarkan syarat syarat yang telah ditetapkan.

3. Job knowledge, yaitu pengetahuan tentang pekerjaan dan keterampilannya.

4. Creativeness, yaitu keaslian gagasan yang dimunculkan dan tindakan-tindakan untuk menyelesaikan persoalan-persoalan yang timbul;

5. Cooperative, yaitu kesediaan untuk bekerja sama dengan orang lain dalam unit kerja masingmasing;

6. Dependability, yaitu kesadaran dan dapat dipercaya dalam hal kehadiran dan penyelesaian pekerjaan;

7. Initiative, yaitu semangat untuk melaksanakan tugas-tugas yang baru dan memperbesar tanggung jawab;

8. Personal qualities, yaitu menyangkut kepribadian, kepemimpinan, keramahtamahan, dan integrasi pribadi.

\subsection{Pengertian Pelatihan BLC}

Broadbrand Learning Center jika dilihat dari susunan kata dalam Bahasa Indonesia mengandung arti Broadbrand merupakan sebuah istilah dalam internet yang memiliki arti koneksi internet transmisi data kecepatan tinggi, learning adalah belajar, kemudian center adalah pusat. Jika pengertian tersebut disimpulkan, maka Broadbrand Learning Center adalah pusat belajar yang menggunakan koneksi internet tranmisi data dengan kecepatan tinggi. Sedangkan menurut situs resmi Pemerintah Kota Surabaya, yaitu www.surabaya.go.id menyebutkan Broadbrand Learning Center (BLC) merupakan fasilitas pembelajaran IT yang dapat dinikmati oleh masyarakat Surabaya secara gratis. Jadi, semakin banyak masyarakat Surabaya yang mengetahui keberadaan dan manfaat BLC, semakin cepat masyarakat Surabaya menjadi tidak gaptek IT.

\section{METODOLOGI PENELITIAN}

\subsection{Jenis Penelitian}

Jenis penelitian yang digunakan penelitian ini adalah penelitian diskriptif kuantitatif. Menurut Sugiyono (2015):"Metode penelitian kuantitatif dapat diartikan sebagai metode 
penelitian yang berlandaskan pada filsafat positifisme, digunakan untuk meneliti pada populasi atau sampel tertentu, pengumpulan data menggunakan instrument penelitian, analisis data bersifat kuantitatif/statistik, dengan tujuan untuk menguji hipotesis yang telah ditetapkan.

Penelitian ini dilakukan pada Kantor Kelurahan Kandangan, Kelurahan Romokalisari, Kelurahan Sememi, Kelurahan Tambak Oso Wilangun dan Kantor Kecamatan Benowo. Populasi dan sampel dalam penelitian ini adalah seluruh Pegawai Negeri Sipil bidang pemerintahan di Wilayah Surabaya Barat sebanyak 82 orang.

\subsection{Analisis Data}

\section{A. Korelasi Berganda}

Menurut Sugiyono (2013 : 231) Merupakan angka yang menunjukan arah dan kuatnya hubungan antara dua variabel secara bersama-sama atau lebih dengan variabel yang lain

Berikut ini adalah rumus perhitungaan korelasi berganda:

$$
R_{y} \cdot x_{1} \cdot x_{2}=\sqrt{\frac{\left(\mathrm{r}_{\mathrm{yx} 1}\right)^{2}+\left(\mathrm{r}_{\mathrm{yx} 2}\right)^{2}-2 \mathrm{Xr}_{\mathrm{yx} 1} \mathrm{Xr}_{\mathrm{yx} 2} \mathrm{Xr}_{\mathrm{x} 1 \mathrm{y} 2}}{1-\mathrm{r}_{\mathrm{x} 1 \mathrm{x} 2}}}
$$

Dimana :

$\mathrm{R}_{\mathrm{y} \times \mathrm{x} 1 . \times 2}$ : Korelasi antara variabel $\mathrm{X}_{1}$ dengan variabel $\mathrm{X}_{2} \quad$ secara bersama-sama dengan variabel $\mathrm{Y}$

$\mathrm{r}_{\mathrm{yx} 1} \quad$ : Korelasi product moment antara $\mathrm{X}_{1}$ dengan $\mathrm{Y}$

$\mathrm{r}_{\mathrm{yx} 2} \quad$ : Korelasi product moment antara $\mathrm{X}_{2} \mathrm{X}$ dengan $\mathrm{Y}$

$\mathrm{r}_{\mathrm{x} 1 \times 2} \quad$ : Korelasi product moment antara $\mathrm{X}_{1}$ dengan $\mathrm{X}_{2}$

Sumber : (Sugiyono, 2013)

Interprestasi dari nilai - nilai koefisien adalah sebagai berikut : a) Jika $\mathrm{r}=0$ atau mendekati 0 maka hubungan dengan kedua variabel tersebut lemah atau tidak ada hubungannya.

b) Jika $\mathrm{r}=+1$ atau mendekati +1 maka hubungan kedua variabel tersebut kuat dan positif. Korelasi positif menunjukkan hubungan yang searah, dimana kenaikan variabel $\mathrm{X}$ akan selalu diikuti dengan variabel $\mathrm{Y}$ atau sebaliknya. 
c) Jika $\mathrm{r}=-1$ atau mendekati -1 maka hubungan tersebut kuat dan negative, korelasi tersebut menunjukan arah yang berlawanan atau sebaliknya.

\section{B. Uji t}

Menurut Suliyanto (2011 : 57).Nilai $\mathrm{t}$ hitung digunakan untuk menguji pengaruh secara parsial (pervariabel) terhadap variabel tergantungnya. Apakah variabel tersebut memiliki pengaruh yang berarti variabel tergantungnya atau tidak

Rumus :

$$
t=\frac{\mathrm{r} \sqrt{\mathrm{n}-2}}{\sqrt{1-\mathrm{r}^{2}}}
$$

Keterangan :

r $\quad$ : Koefisen Korelasi

n : Jumlah yang diteliti

\section{Uji F}

Menurut Suliyanto (2011 : 58). Uji

F hitung digunakan untuk menguji pengaruh secara simultan variabel bebas terhadap variabel tergantungnya. Jika variabel bebas mempunyai pengaruh secara simultan terhadap variabel tergantung maka model persamaan regresi masuk dalam kriteria cocok atau fit. Sebaaliknya jika tidak terdapat pengaruh secara simultan maka masuk kategori tidak cocok atau non fit.

Rumus :

$$
F_{\text {hitung }}=\frac{\frac{R^{2}}{K}-1}{\frac{\left(1-R^{2}\right)}{(n-K)}}
$$

Keterangan :

$\mathrm{R}^{2}$

: Korelasi parsial yang ditemukan

n : jumlah sampel

K : Jumlah vriabel bebas Sumber : (Suliyanto, 2011).

Kriteria penerimaan atau penolakan : $\mathrm{F}_{\text {hitung }} \geq \mathrm{F}_{\text {tabel }}$ berarti $\mathrm{H}_{0}$ ditolak. $\mathrm{F}_{\text {hitung }} \leq \mathrm{F}_{\text {tabel }}$ berarti $\mathrm{H}_{0}$ diterima.

\section{HASIL PENELITIAN DAN PEMBAHASAN}

\subsection{Analisis Regresi Linier Berganda}

Menurut Suliyanto (2011 : 54) Analisis regresi linier berganda digunakan untuk memprediksi nilai dari variabel disiplin kerja (X1) dan variabel pelatihan BLC (X2). Melalui prediksi ini dapat diketahui besarnya pengaruh kedua variable tersebut terhadap kinerja pegawai negeri sipil (Y) di Wilayah Kecamatan Benowo Kota Surabaya. Hasil uji analisis regresi linier berganda dalam penelitian ini dapat dilihat pada hasil program SPSS dalam tabel berikut : 
Tabel 1. Uji Regresi Linier Berganda

\begin{tabular}{|c|c|c|c|c|c|c|}
\hline \multirow{2}{*}{\multicolumn{2}{|c|}{ Model }} & \multicolumn{2}{|c|}{ Unstandardized Coefficients } & \multirow{2}{*}{$\begin{array}{c}\text { Standardized } \\
\text { Coefficients } \\
\text { Beta } \\
\end{array}$} & \multirow[b]{2}{*}{$\mathrm{t}$} & \multirow[b]{2}{*}{ Sig. } \\
\hline & & $\mathrm{B}$ & Std. Error & & & \\
\hline \multirow[t]{3}{*}{1} & (Constant) & 2,402 & 0,996 & & 2,412 & 0,019 \\
\hline & $\mathrm{X} 1$ & 0,360 & 0,115 & 0,360 & 3,118 & 0,003 \\
\hline & $\mathrm{X} 2$ & 0,419 & 0,096 & 0,504 & 4,367 & 0,000 \\
\hline
\end{tabular}

Sumber : Data diolah dengan SPSS versi 23.0

Berdasarkan pengolahan data yang terlihat pada table diatas, kolom kedua bagian B, maka diperoleh persamaan regresi linier berganda :

$$
Y=2,402+0,360 X_{1}+0,419 X_{2}
$$

Persamaan regresi linier berganda tersebut diatas dapat diuraikan sebagai berikut :

1) Nilai konstanta sebesar 2,402 , hal ini berarti bahwa jika jumlah disiplin kerja dan pelatihan BLC tetap/tidak mengalami penambahan/pengurangan, maka jumlahnya sebesar nilai konstanta yaitu 2,402 .

2) Koefisien regresi $\left(X_{1}\right)=0,360$ menunjukan bahwa berpengaruh positif dan signifikan. Hal ini mengandung arti bahwa setiap kenaikan jumlah disiplin kerja $\left(\mathrm{X}_{1}\right) \quad 1 \%$ maka variable kinerja pegawai negeri sipil (Y) di Wilayah Kecamatan Benowo Kota Surabaya akan naik 0,360\% dengan asumsi bahwa variabel bebas lain dari model regresi adalah tetap.

3) Koefisien regresi Pelatihan BLC $\left(X_{2}\right)=0,419$ menunjukan bahwa berpengaruh positif dan signifikan. Hal ini mengandung arti bahwa setiap kenaikan Pelatihan BLC $\left(\mathrm{X}_{2}\right) \quad 1 \%$ maka variabel Kinerja Pegawai Negeri Sipil (Y) di Wilayah Kecamatan Benowo Kota Surabaya akan naik $0,419 \%$ dengan asumsi bahwa variabel bebas lain dari model regresi adalah tetap.

\subsection{Hasil Uji t dan Uji F}

Menurut Suliyanto, (2011 : 55) Nilai $\mathrm{t}$ hitung digunakan untuk menguji pengaruh secara parsial (per variable) terhadap variable tergantungnya. Apakah variabel tersebut memiliki pengaruh yang berarti terhadap variabel tergantungnya atau tidak. 
Berdasarkan pengolahan data yang terlihat pada tabel diatas, maka dapat diuraikan sebagai berikut :

1) Pengaruh disiplin kerja $\left(X_{1}\right)$ terhadap kinerja pegawai (Y) di Wilayah Kecamatan Benowo Kota Surabaya pada hasil tabel diatas terbaca untuk variabel disiplin kerja $\left(\mathrm{X}_{1}\right)$ nilai $\mathrm{t}_{\text {hitung }}=3,118$ dan $\mathrm{t}_{\text {tabel }}=$ 2,00247. Jadi $t_{\text {hitung }}>t_{\text {tabel }}=3,118>$ 2,00247 berarti $\mathrm{H}_{0}$ ditolak $\mathrm{H}_{\mathrm{a}}$ diterima, dengan tingkat signifikan sebesar 0,003. Artinya menunjukan bahwa disiplin kerja $\left(\mathrm{X}_{1}\right)$ berpengaruh dan signifkan secara parsial terhadap kinerja pegawai negeri sipil (Y) di Wilayah Kecamatan Benowo Kota Surabaya.

2) Pengaruh Pelatihan BLC $\left(X_{2}\right)$ terhadap kinerja Pegawai Negeri Sipil (Y) di Wilayah Kecamatan Benowo Kota Surabaya pada hasil tabel terbaca untuk variabel Pelatihan BLC $\left(\mathrm{X}_{2}\right)$ nilai $\mathrm{t}_{\text {hitung }}=$ 4,367 dan $t_{\text {tabel }}=2,00247$. Jadi $t_{\text {hitung }}$ $>\mathrm{t}_{\text {tabel }}=4,367>2,00247$ berarti $\mathrm{H}_{0}$ ditolak $\mathrm{H}_{\mathrm{a}}$ diterima, dengan tingkat signifikan sebesar 0,000. Artinya menunjukan bahwa Pelatihan BLC $\left(\mathrm{X}_{2}\right)$ berpengaruh dan signifikan secara parsial terhadap (Y) di Wilayah Kecamatan Benowo Kota Surabaya.

Tabel 2. ANOVA

\begin{tabular}{|rr|r|r|r|r|r|}
\hline Model & & Sum of Squares & Df & Mean Square & F & Sig. \\
\hline 1 & Regression & 82,378 & 2 & 41,189 & 52,634 & 0,000 \\
& Residual & 44,606 & 57 & 0,783 & & \\
& Total & 126,983 & 59 & & & \\
& & & & & \\
\hline
\end{tabular}

Sumber : Data diolah dengan SPSS versi 23.0

Berdasarkan dari pengolahan data yang terlihat pada table diatas diketahui bahwa $\mathrm{F}_{\text {hitung }}=52,634$ dan $\mathrm{F}_{\text {tabel }}=3,16$ . jadi $F_{\text {hitung }}>F_{\text {tabel }}=52,634>3,16$ berarti $\mathrm{H}_{0}$ ditolak $\mathrm{H}_{\mathrm{a}}$ diterima, dengan tingkat dignifikan 0,000 artinya menunjukan bahwa memang terdapat pengaruh dan signifikan secara simultan antara disiplin kerja $\left(\mathrm{X}_{1}\right)$, pelatihan BLC $\left(\mathrm{X}_{2}\right)$ dengan Kinerja Pegawai Negeri Sipil (Y) di Wilayah Kecamatan Benowo Kota Surabaya. 


\section{PENUTUP}

\subsection{Simpulan}

Berdasarkan hasil pembahasan analisis data dalam bab sebelumnya, maka dapat ditarik kesimpulan sebagai berikut : Antara disiplin kerja dan pelatihan BLC, variabel yang memiliki pengaruh paling dominan terhadap kinerja pegawai negeri sipil di Wilayah Kecamatan Benowo Kota Surabaya adalah variabel pelatihan BLC. Karena dari hasil penelitian Koefisien Beta menunjukan bahwa nilai variabel disiplin kerja sebesar 0,360. Sedangkan nilai variabel pelatihan BLC sebesar 0,504. Oleh karena nilai variabel pelatihan BLC lebih besar, maka yang paling dominan berpengaruh terhadap kinerja pegawai negeri sipil di Wilayah Kecamatan Benowo Kota Surabaya.

\subsection{Saran}

Setelah dilakukan penelitian dan menghasilkan suatu kesimpulan, maka penelitian mencoba untuk memberikan saran yang kiranya dapat bermanfaat :

1. Diharapkan untuk dapat meningkatkan disiplin kerja agar dapat lebih maksimal melayani masyarakat khususnya yang ada di Wilayah Kecamatan Benowo Kota Surabaya.
2. Memanfaatkan secara maksimal program pelatihan Broadbrand Learning Center (BLC)

\section{DAFTAR PUSTAKA}

Arikunto, Suharsimi., 2012, Prosedur Penelitian : Suatu Pendekatan Praktek, Jakarta : Rineka Cipta

Dessler, Gary, 2015. Manajemen Sumber Daya Manusia, Jakarta : Salemba Empat

Ghozali, Imam, 2009. Aplikasi Analisis Multivariate Dengan Program IBM SPSS 19. Semarang : Universitas Diponegoro

Gomez, Faustiono Cardoso. 2010. Mana jemen Sumber Daya Manusia. Yogyakarta : Andy Offset

Hasibuan, Malayu, SP. 2008. Manajemen Sumber Daya Manusia. Jakarta : Bumi Aksara

Mangkunegara, Anwar Prabu, 2010. Evaluasi Kinerja SDM. Bandung : Refika Aditama

Mangkuprawira, S.Tb, 2010. Manajemen Sumber Daya Manusia Strategik, Bogor : Ghalia Indonesia

Nugroho, J, 2015. Perilaku Konsumen : Konsep dan Implikasi Untuk Strategi dan Penelitian Pemasaran. Jakarta : Kencana 
Noor, Juliansyah, 2012. Metodologi

Penelitian. Jakarta : Kencana Prenada Media Group

Simamora, Henry, 2006. Manajemen Sumber Daya Manusia Edisi Ketiga. Yogyakarta : Penerbit STE YKPN

Suliyanto. 2011. Ekonometrika Terapan

: Teori dan Aplikasi dengan SPSS.

Yogyakarta : Andi

www.surabaya.go.id (diakses tanggal 22 April 2017) 